\title{
PRODUÇÃO E QUALIDADE FISIOLÓGICA DE SEMENTES DE FEIJÃO-VAGEM EM FUNÇÃO DE FONTES E DOSES DE NITROGÊNIO ${ }^{1}$
}

\author{
ADEMAR P. DE OLIVEIRA ${ }^{1,6}$, EUSINIA L. PEREIRA², RISELANE DE LUCENA ALCÂNTARA BRUNO ${ }^{1}$, EDNA U. ALVES³, \\ RUBENS F. DA COSTA ${ }^{4}$, FRANCISCO ROMEU F. LEAL ${ }^{5}$
}

\begin{abstract}
RESUMO - Estudaram-se os efeitos da aplicação de cinco doses e três fontes de nitrogênio sobre a produção e a qualidade fisiológica de sementes de feijão-vagem, cv. Macarrão Trepador Hortivale, no período de setembro/2000 a fevereiro/2001, no Centro de Ciências Agrárias da Universidade Federal da Paraíba, em Areia. O delineamento experimental utilizado foi em blocos casualizados, com os tratamentos distribuídos em esquema fatorial $(3 \times 5)+1$, correspondendo às fontes (nitrato de cálcio, sulfato de amônio e uréia) e doses (0, 25, 50, 75 e 100kg.ha-1) de nitrogênio, e um tratamento adicional sem adubação (testemunha), com quatro repetições. As fontes nitrato de cálcio e sulfato de amônio, na dose de $100 \mathrm{~kg} . \mathrm{ha}^{-1}$, e uréia, na dose de $55 \mathrm{~kg} . \mathrm{ha}^{-1}$ de $\mathrm{N}$, proporcionaram as produções de sementes no feijão-vagem de $2.571,3.219$ e $2.221 \mathrm{~kg} \cdot \mathrm{ha}^{-1}$, respectivamente. O nitrogênio, em todas as fontes, influenciou positivamente a germinação e o vigor (índice de velocidade de germinação e emergência em campo) da semente do feijão-vagem. As doses de 68,8 e 49kg.ha-1 de $\mathrm{N}$, fontes nitrato de cálcio e uréia foram responsáveis pelos valores máximos para a porcentagem de germinação, 72 e 75\%, respectivamente. Para a fonte sulfato de amônio ocorreu aumento linear da porcentagem de germinação, à medida que se elevaram as doses de nitrogênio, sendo que na dose de $100 \mathrm{~kg}$.ha-1 obteve-se um porcentual de $84 \%$. O índice de velocidade de germinação apresentou valores mais elevados, 6,0; 7,7 e 6,9 nas doses de 49; 71 e 53kg.ha-1 de N, fontes nitrato de cálcio, uréia e sulfato de amônio, respectivamente. A emergência em campo aumentou linearmente com elevação das doses de $\mathrm{N}$ (fonte nitrato de cálcio), sendo a emergência máxima (70\%) obtida na dose de $100 \mathrm{~kg} \mathrm{ha}^{-1}$ de $\mathrm{N}$ em cada fonte. O sulfato de amônio deve ser recomendado como fonte de $\mathrm{N}$, em programas de produção de sementes de feijão-vagem.
\end{abstract}

Termos para indexação: Phaseolus vulgaris L., sementes, adubação, germinação, vigor, rendimento.

\section{YIELD AND QUALITY OF SNAP-BEAN SEEDS AS FUNCTION SOURCES AND LEVELS OF NITROGEN}

\begin{abstract}
The application of three nitrogen sources in five concentrations each were studied in the physiological quality and yield of snap-bean seeds, cv. Macarrão Trepador Hortivale, from September/2000 to February/2001, in the Centro de Ciências Agrárias of the Universidade Federal of Paraíba, in Areia. A randomized complete block design was used, with treatments distributed in factorial scheme of (3 x 5) + 1, corresponding to nitrogen sources (calcium nitrate, ammonium sulfate and urea) and the second the five $\mathrm{N}$ levels $\left(0,25,50,75\right.$ and $\left.100 \mathrm{~kg}^{-h a^{-1}}\right)$, and an additional treatment (without fertilization), in four replications. At $100 \mathrm{~kg}^{-h a^{-1}}$ of $\mathrm{N}$, the sources nitrate of calcium and sulfate of ammonium and urea at $55 \mathrm{~kg} \mathrm{ha}^{-1}$ of $\mathrm{N}$ presented the highest snap-bean seed yields, $2.571,3.219$ and $2.221 \mathrm{~kg} . \mathrm{ha}^{-1}$, respectively, which surpassed the national average by $1.517,1.219$ and $1.221 \mathrm{~kg} \mathrm{ha}^{-1}$. The $\mathrm{N}$ in all the sources influenced the germination and the vigor positively (germination speed index and field emergence) of snap-bean seeds. At 68,8 and 49kg.ha-
\end{abstract}

1 Aceito para publicação em 31.05.2003.

1,6 CCA-UFPB; Cx. Postal 02, 58397-000, Areia, PB; bolsista CNPq; email: ademar@cca.ufpb.br;

2 Programa de Pós-Graduação em Agronomia, CCA-UFPB.
Curso de Doutorado em Produção e Tecnologia de Sementes, FCAVUNESP; Jaboticabal, SP.

4 EMEPA-PB, 58316-000, Alagoinha, PB.

5 Curso de Agronomia, CCA-UFPB. 


\begin{abstract}
${ }^{1}$ of $\mathrm{N}$, calcium nitrate and urea were responsible for the maximum values for germination percentage, $72 \%$ and $75 \%$, respectively. For ammonium sulfate there was a linear increase in the germination percentage, as the levels of $\mathrm{N}$ increased and at $100 \mathrm{~kg} \cdot \mathrm{ha}^{-1}$ of $84 \%$ germination was obtained. The germination speed Index showed higher values, 6,0; 7,7 and 6,9 at 49; 71 and 53 $\mathrm{kg} \cdot \mathrm{ha}^{-1} \mathrm{~N}$, calcium nitrate, urea and ammonium sulfate, respectively. The field emergence increased linearly with calcium nitrate concentrations reaching the maximum emergence (70\%) obtained at the $100 \mathrm{~kg} \mathrm{ha}^{-1} \mathrm{~N}$ concentration in each source. The ammonium sulfate should be recommended as a source of $\mathrm{N}$, in snap-bean seed production programs.
\end{abstract}

Index terms: Phaseolus vulgaris L., seeds, fertilization, germination, vigour

\section{INTRODUÇÃO}

Nos campos de produção sementes, o uso de fertilizantes é mais comum do que nas lavouras de consumo, isso porque, as condições do solo, no tocante a composição e disponibilidade de nutrientes para as plantas, influem na produção e na qualidade da semente, por afetar a formação do embrião e dos órgãos de reserva, assim como a composição química (Carvalho \& Nakagawa, 2000). O emprego de fórmulas equilibradas, contendo, fósforo e potássio, aliado à aplicação de nitrogênio, em dose e tempo certo, estimula a produção de sementes (Toledo \& Marcos Filho, 1977). Contudo, o número de experimentos relacionados especialmente com essa finalidade é limitado, de modo que o emprego de fertilizantes é feito com base nos resultados obtidos para as respectivas culturas de consumo.

O nitrogênio é um macronutriente primário, essencial para as plantas, por participar da formação de proteínas, aminoácidos e de outros compostos importantes no metabolismo das plantas. Sua ausência bloqueia a síntese de citocinina, hormônio responsável pelo crescimento das plantas, causando redução do seu tamanho e consequentemente redução da produção econômica das sementes (Mengel \& Kirkby, 1982).

Em algumas hortaliças tais como cebola, Khomenmko \& Lysyuv (1981) obtiveram maior produção de sementes utilizando 180kg.ha-1 de nitrogênio. No quiabeiro, cultivar Campinas IAC-4076, Zanin \& Mota (1995) constataram elevação na produção de sementes aplicando sulfato de amônio, metade na semeadura e metade na floração. Na cultura do coentro, Bezerra \& Assunção (1995) evidenciaram a influência positiva do nitrogênio sobre a produtividade de sementes, sendo a dose de $90 \mathrm{~kg} \cdot \mathrm{ha}^{-1}$ de $\mathrm{N}$ responsável pela maior produtividade.

Tratando-se da produção de sementes do feijão-vagem, alguns autores apontam o Nordeste como região ideal para sua produção, principalmente o semi-árido, contudo, não mencionam os efeitos da adubação sobre a produção e qualidade das sementes. Com este objetivo e devido à falta de resultados de pesquisas, Viggiano (1990), recomenda que a adubação química para o feijão-vagem deve ser baseada nos resultados de análise do solo e calculada para o feijão-comum, por se tratar da mesma espécie e do mesmo produto final, a semente. Para as condições de Areia-PB, Alves et al. (2000) recomendam o emprego de esterco bovino na dose de 25t.ha ${ }^{-1}$.

Os efeitos da adubação nitrogenada sobre a qualidade fisiológica de sementes, são um tanto controversos em diversas culturas. No feijão-comum, Carvalho et al. (1999), constataram influência de fontes e formas de aplicação de nitrogênio na qualidade fisiológica das sementes. No entanto, Paulino et al. (1999) e Ambrosano et al. (1999) não verificaram diferenças significativas entre as fontes e formas de parcelamento do nitrogênio na qualidade fisiológica das sementes desse feijão. Do mesmo modo, em estudos com sementes de quiabo (Zanin \& Mota, 1995) e de cebola (Thomazelli et al., 1992), não encontraram efeito significativo do nitrogênio na qualidade das sementes.

Diante do exposto, o trabalho teve como objetivo avaliar a influência de fontes e doses de nitrogênio sobre a produção e qualidade fisiológica de sementes no feijão-vagem.

\section{MATERIAL E MÉTODOS}

Dois experimentos foram conduzidos no Centro de Ciências Agrárias da Universidade Federal da Paraíba em Areia, durante o período de setembro/2000 a fevereiro/2001, em campo e em laboratório. O experimento de campo teve como objetivo avaliar a produção de sementes em Latossolo Vermelho-Amarelo, onde foram estabelecidos 16 tratamentos, constituídos de cinco doses $\left(0,25,50,75\right.$ e $\left.100 \mathrm{~kg} \cdot \mathrm{ha}^{-1}\right)$ e três fontes (nitrato de cálcio, sulfato de amônio e uréia com 18, 20 e $45 \%$ de $\mathrm{N}$, respectivamente) mais um tratamento adicional (testemunha sem nenhuma adubação), em blocos 
casualizados, distribuídos em esquema fatorial (3 x 5) + 1, em quatro repetições. A análise química do solo indicou as seguinte características: $\mathrm{pH}\left(\mathrm{H}_{2} \mathrm{O}\right)=6,10 ; \mathrm{P}=46 \mathrm{mg} / \mathrm{dm}^{3} ; \mathrm{K}$ $=95,00 \mathrm{mg} / \mathrm{dm}^{3} ; \mathrm{Ca}=2,50 \mathrm{cmol}_{\mathrm{c}} \mathrm{dm}^{3} ; \mathrm{Mg}=0,90 \mathrm{cmol}_{\mathrm{c}} / \mathrm{dm}^{3} \mathrm{e}$ matéria orgânica $=13,0 \mathrm{~g} / \mathrm{dm}^{3}$.

O solo foi preparado mediante aração, gradagem, levantamento de leirões e abertura de covas de plantio. Na adubação de plantio aplicaram-se $500 \mathrm{~kg} \cdot \mathrm{ha}^{-1}$ de superfosfato simples, $100 \mathrm{~kg} \cdot \mathrm{ha}^{-1}$ de cloreto de potássio e $20 \mathrm{t}^{-h^{-1}} \mathrm{de}^{\mathrm{d}}$ esterco bovino. Na adubação de cobertura, foram aplicadas as doses e fontes de nitrogênio definidas no delineamento experimental, parceladas $50 \%$ aos 20 e $50 \%$ aos 40 dias após a semeadura. As parcelas mediram $10 \mathrm{~m}^{2}$, contendo 20 covas, espaçadas de $1,00 \mathrm{~m}$ entre fileiras e $0,50 \mathrm{~m}$ entre plantas, todas consideradas úteis.

O plantio foi realizado pelo método de semeadura direta, utilizando-se quatro sementes por cova, do cultivar Macarrão Trepador produzido pela Hortivale-PE, com 92\% de germinação e 99,9\% de pureza. Aos 15 dias, realizou-se o desbaste, permitindo-se a permanência de duas plantas por cova, e a prática de tutoramento, pelo método de varas cruzadas.

Procurou-se manter as plantas sempre no limpo, por meio de capinas, com auxílio de enxadas para evitar a concorrência com as plantas daninhas. Foram efetuadas irrigações pelo método de aspersão, com turno de rega de três vezes por semana, nos períodos de ausência de chuvas. Realizou-se controle fitossanitário, por meio da aplicação de Benomyl (20g/ 20 litros de $\mathrm{H}_{2} \mathrm{O}$ ) para controlar mancha de alternaria (Alternaria alternata), ferrugem (Uromyces appendiculatus) e mancha angular (Phaeoisariopsis griseola).

Os efeitos das doses de nitrogênio sobre a produção de sementes foram avaliados através da colheita de todas as sementes de cada parcela aos 80 dias após a semeadura.

O experimento em laboratório foi conduzido para a avaliação da qualidade fisiológica das sementes produzidas. $\mathrm{O}$ delineamento experimental utilizado foi inteiramente casualizado, com quatro repetições, avaliando-se os efeitos dos mesmos tratamentos empregados para obtenção das sementes, também distribuídos no esquema fatorial (3 x 5) + 1 . Neste experimento, a qualidade das sementes foi avaliada por meio dos seguintes testes:

Teste de germinação: utilizando-se quatro repetições de 50 sementes por tratamento distribuídas em substrato papel "germitest" umedecido com água destilada no volume de 2,5 vezes o peso do papel seco, organizados em forma de rolo e mantidos em sacos plásticos no germinador a temperatura de $25^{\circ} \mathrm{C}$. As contagens foram realizadas aos cinco e nove dias após a semeadura, sendo as avaliações feitas de acordo com as Regras para Análise de Sementes (Brasil, 1992);

Índice de velocidade de germinação: efetuado conjuntamente com o teste de germinação, onde a partir do quinto dia após a semeadura foi feita a contagem do número de sementes germinadas, sendo repetida diariamente até o nono dia. O índice de velocidade de germinação foi calculado de acordo com Maguire (1962);

Emergência em campo: utilizando-se 200 sementes (quatro repetições de 50 sementes) por tratamento, semeadas em sulcos de $1,50 \mathrm{~m}$ de comprimento, espaçadas a $0,20 \mathrm{~m}$ à uma profundidade de $4,0 \mathrm{~cm}$. A contagem foi efetuada considerando-se o número total de plantas emergidas no $21^{\circ}$ dia após a semeadura (Vieira \& Carvalho, 1994).

Os efeitos das fontes e doses de $\mathrm{N}$ sobre as características avaliadas foram conhecidos mediante análise de variância, utilizando-se o "software" SAEG (2000), em desdobramento da soma de quadrado da interação (fontes e doses de nitrogênio) independente de sua significância. Dentro de cada dose e fonte de nitrogênio, foram testados diversos modelos polinomiais para avaliar seus efeitos. O critério para a escolha do modelo foi a significância pelo teste $\mathrm{F}$ ao nível de 5\% de probabilidade e que tenha apresentado a maior ordem para o coeficiente de determinação $\left(\mathrm{R}^{2}\right)$.

\section{RESULTADOS E DISCUSSÃO}

\section{Produção de sementes}

A equação representativa da produção de sementes de feijão-vagem, em função das doses de $\mathrm{N}$ fornecidas na forma de nitrato de cálcio apresentou um ponto de mínimo (Figura 1). Pela sua derivação, calculou-se a dose de $32 \mathrm{~kg} \cdot \mathrm{ha}^{-1}$ de $\mathrm{N}$, como aquela responsável pela produção mínima estimada em $1.551 \mathrm{~kg}$.ha- ${ }^{-1}$ de sementes, sendo os mais elevados valores para a produção, obtidos na ausência de $\mathrm{N}$ em cobertura (1.782kg.ha $\left.{ }^{-1}\right)$ e na dose máxima (2.571 kg.ha- $\left.{ }^{-1}\right)$. Comparando esses valores com a produção obtida na testemunha $\left(810 \mathrm{~kg} \cdot \mathrm{ha}^{-1}\right)$, verifica-se que a produção mínima superou a testemunha em $741 \mathrm{~kg}^{-h a^{-1}}$, na ausência de $\mathrm{N}$ em cobertura a diferença foi de $972 \mathrm{~kg} \mathrm{ha}^{-1}$, e de $1.761 \mathrm{~kg}$.ha- ${ }^{-1}$ de sementes na dose máxima de $\mathrm{N}$.

Ocorreu aumento linear da produção de sementes de feijão-vagem em função das doses de $\mathrm{N}$ na forma de sulfato de amônio com incremento na ordem de $15 \mathrm{~kg} \cdot \mathrm{ha}^{-1} \mathrm{de}$ sementes a cada quilograma de $\mathrm{N}$ adicionado ao solo, obtendo-se na dose máxima a produção de $3.219 \mathrm{~kg}_{\text {g.ha }}{ }^{-1}$. Esta produção superou a testemunha em $2.409 \mathrm{~kg}$ ha $^{-1}$ de sementes (Figura 1). 


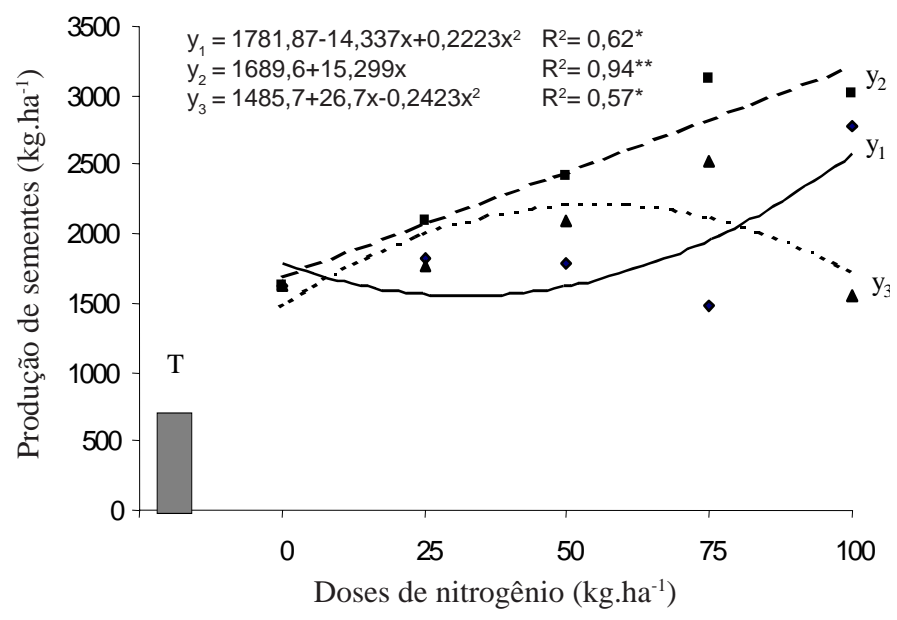

FIG. 1. Produção de sementes de feijão-vagem, cv. Macarrão Trepador, em função de doses de nitrogênio, fontes nitrato de cálcio $\left(\mathrm{y}_{1}\right)$, sulfato de amônio $\left(\mathrm{y}_{2}\right)$ e uréia $\left(\mathbf{y}_{3}\right)$. Areia, 2002.

As médias da produção de sementes de feijão-vagem, em função das doses de $\mathrm{N}$ fornecidas na forma de uréia ajustaram-se ao modelo quadrático de regressão (Figura 1), onde pela sua derivação calculou-se a dose de $55 \mathrm{~kg}_{\mathrm{a}} \mathrm{ha}^{-1} \mathrm{de} \mathrm{N}$, como aquela responsável pela produção máxima estimada em $2.221 \mathrm{~kg}$ ha $^{-1}$ de sementes. Esta dose, embora baixa quando comparada com aquelas responsáveis pela produção máxima de sementes nas fontes nitrato de cálcio e sulfato de amônio, provavelmente permitiu à planta a capacidade máxima de produção de sementes. Também, a produção obtida, com esta dose, foi superior a obtida pela testemunha de $1.411 \mathrm{~kg} \cdot \mathrm{ha}^{-1}$ de sementes.

As produções máximas proporcionadas pelo fornecimento de $\mathrm{N}$ nas formas de nitrato de cálcio (2.517kg.ha- $\left.{ }^{-1}\right)$, de sulfato de amônio (3.219kg.ha- $\left.{ }^{-1}\right)$ e de uréia $\left(2.221 \mathrm{~kg} \cdot \mathrm{ha}^{-1}\right)$, superaram a produção média nacional de sementes (2,0t.ha-1 $\left.{ }^{-1}\right)$ para cultivares de feijão-vagem com hábito de crescimento indeterminado, definido por Viggiano (1990). Em feijão-comum, Valério et al. (1999), Carvalho et al. (2000), Barbosa Filho \& Silva (2001) verificaram elevação na produção de grãos em função do fornecimento de N. No feijão-caupi (Oliveira et al., 1999), no coentro (Bezerra \& Assunção, 1995), na cebola (Khomenmko \& Lysyuv, 1981; Thomazelli et al., 1992), na pimenta-do-reino (Veloso et al., 2000) e no pimentão (Silva et al., 1999), houve elevação na produção de sementes, também em função do fornecimento de N.

Embora os teores de P (45,56mg.dm $)$ e K (95,00mg.dm³), originalmente no solo, fossem, respectivamente, bom e médio (Raij, 1991), os resultados obtidos para a produção de sementes em função do fornecimento de N, devem-se, em parte, ao baixo teor de matéria orgânica (1,3\%). De acordo com Pottker \& Roman (1994), o teor de matéria orgânica tem sido classicamente utilizado para estimar a disponibilidade de nitrogênio e, consequentemente, a necessidade de adubação às culturas. Teixeira et al. (1994) enfatizaram que, em solos degradados, os baixos teores de matéria orgânica podem determinar menor disponibilidade de nitrogênio às culturas, resultando numa das principais limitações à produtividade agrícola.

A elevação na produção de sementes indicou que, provavelmente durante o crescimento e desenvolvimento das plantas, o nitrogênio fornecido, juntamente com os nutrientes contidos no solo, possivelmente supriram eficientemente as necessidades nutricionais do feijão-vagem, permitindo inferir que o efeito positivo da aplicação das fontes e das doses de nitrogênio foi devido ao suprimento de nutrientes de forma equilibrada nas doses responsáveis pelas produções máximas, conferindo à cultura a capacidade máxima de produção de sementes, induzida pela constituição genética e pela condição do experimento. Segundo Primavesi (1990), o equilíbrio entre os elementos nutritivos proporcionam maiores produtividades do que maiores quantidades de macronutrientes isoladamente. Maiores produções de sementes de feijão-vagem e feijão-caupi em função da adubação organo-mineral balanceada foram relatadas por Alves (1999) e Oliveira et al. (2000), respectivamente. Em quiabeiro, Zanin \& Mota (1995) obtiveram elevação da produção de sementes, em função do fornecimento balanceado do nitrogênio.

A redução na produção de sementes verificada na dose acima de $55 \mathrm{~kg} \cdot \mathrm{ha}^{-1}$ de $\mathrm{N}$, fonte uréia, pode indicar que, seu excesso foi prejudicial ao desenvolvimento do feijão-vagem, possivelmente em conseqüência direta do efeito tóxico do amônio e da baixa taxa de nitrificação ou devido ao efeito indireto do amônio, reduzindo a absorção de outros cátions, isto é, exercendo forte efeito competitivo sobre os cátions $\left(\mathrm{K},{ }^{+} \mathrm{Ca}^{++}\right.$e $\left.\mathrm{Mg}^{++}\right)$de tal forma que a absorção destes seriam reduzidas pela planta (Carnicelli et al., 2000). Huett (1989) verificou redução de produtividade em varias hortaliças, em função de doses elevadas de nitrogênio e Tavares Sobrinho (2001) obteve redução da produtividade de vagens em feijãovagem em função de doses elevadas de nitrogênio, fonte uréia. Segundo Malavolta (1980) o excesso de nitrogênio provoca aumento na duração do estádio vegetativo e queda de produção.

\section{Qualidade da semente}

Teste de germinação e índice de velocidade de germinação 
As médias da porcentagem de germinação, em sementes de feijão-vagem, em função das doses de $\mathrm{N}$, ajustaram-se ao modelo quadrático de regressão para nitrato de cálcio e uréia, enquanto para a fonte sulfato de amônio, o ajuste foi de forma linear, onde as derivadas das equações representativas das fontes nitrato de cálcio e uréia (Figura 2) revelaram as doses de 68,8 e $49 \mathrm{~kg}_{\text {.ha-1 }}{ }^{-1}$ de $\mathrm{N}$ como aquelas responsáveis pelos valores máximos estimados para a porcentagem de germinação, 72 e 75\%, respectivamente. Para sulfato de amônio ocorreu aumento linear na porcentagem de germinação, à medida que se elevaram as doses de nitrogênio, com incremento na ordem de $0,28 \%$ a cada quilograma de $\mathrm{N}$ adicionado ao solo, sendo que na dose máxima obteve-se um percentual de $84 \%$ (Figura 2), superior a percentagem mínima de germinação tolerada para comercialização de sementes de feijão-vagem, definida em 70\%, conforme (Viggiano, 1990).

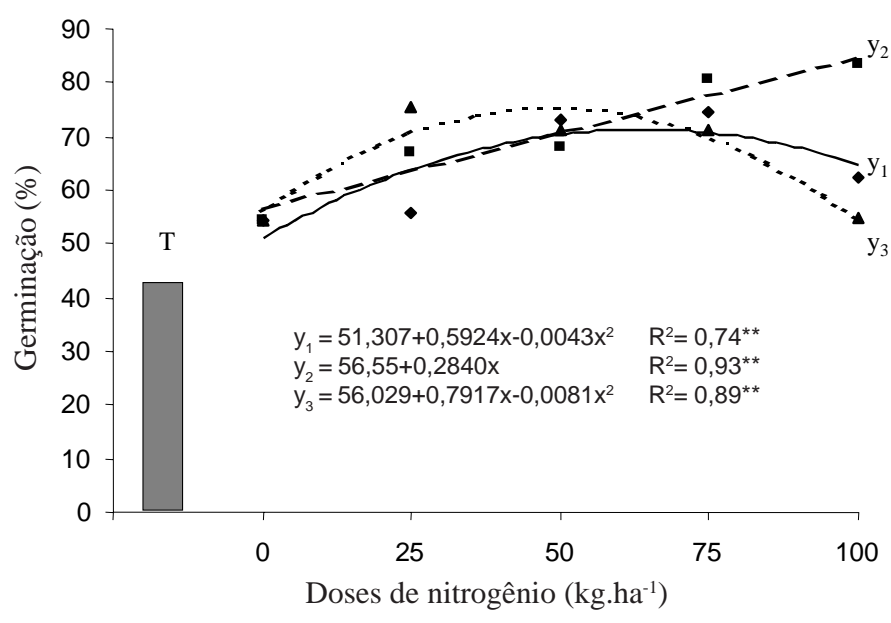

FIG. 2. Porcentagem de germinação de sementes de feijãovagem, cv. Macarrão Trepador, em função de doses de nitrogênio, fontes nitrato de cálcio $\left(y_{1}\right)$, sulfato de amônio $\left(\mathrm{y}_{2}\right)$ e uréia $\left(\mathrm{y}_{3}\right)$. Areia, 2002.

Independente das fontes utilizadas, todas as doses de nitrogênio aplicadas propiciaram porcentagem de germinação superior à testemunha (43\%). Esses resultados, provavelmente estejam relacionados ao fato de que a ação de uma adubação balanceada, durante o estádio vegetativo do feijão-vagem, permitiu o acúmulo de reservas sendo posteriormente translocadas paras as sementes para a formação do embrião e dos órgãos de reserva (Timiriazem, 1979; Carvalho \& Nakagawa, 2000).

Quanto a velocidade de germinação, em todas as fontes de $\mathrm{N}$, as médias ajustaram-se a um modelo quadrático de re- gressão, sendo que, pelas derivações das equações (Figura 3), as doses de 49, 71 e 53kg.ha-1 de $\mathrm{N}$, fontes nitrato de cálcio, sulfato de amônio e uréia, como responsáveis pelos valores máximos estimados de 6,0; 7,7 e 6,9, respectivamente. Na testemunha o valor alcançado para esse índice $(3,6)$, foi inferior àqueles propiciados por nitrato de cálcio, sulfato de amônio e uréia, (2,42; 4,12 e 3,32), respectivamente, demonstrando sulfato de amônio mostrou-se a mais adequada para aumentar este índice em sementes de feijão-vagem.

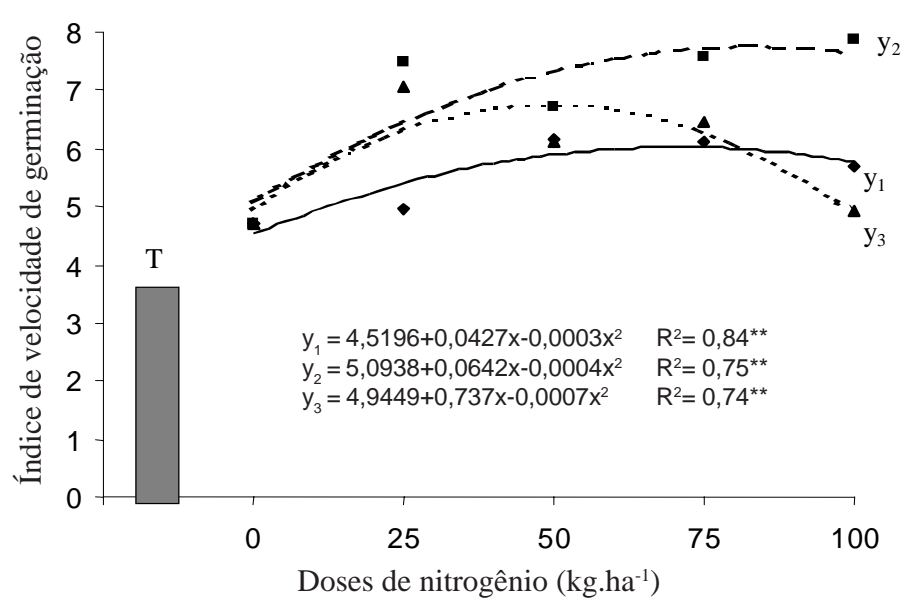

FIG. 3. Índice de velocidade de germinação de sementes de feijão-vagem, cv. Macarrão Trepador, em função de doses de nitrogênio, fontes nitrato de cálcio $\left(\mathrm{y}_{1}\right)$, sulfato de amônio $\left(\mathrm{y}_{2}\right)$ e uréia $\left(\mathrm{y}_{3}\right)$. Areia, 2002.

Tanto na porcentagem como no índice de velocidade de germinação, o sulfato de amônio foi a fonte de nitrogênio que proporcionou os maiores valores (84\% e 7,7), respectivamente. Em sementes de feijão-comum, Soratto et al. (1999) também verificaram incrementos na porcentagem de germinação, em função do aumento de doses de nitrogênio, enquanto Chidi et al. (1999), observaram aumento da taxa de germinação com doses de nitrogênio, aplicadas na forma de uréia, em doses acima de $50 \mathrm{~kg}_{\text {.ha }}{ }^{-1}$, fato este, também constatado nesse estudo. No entanto, Vieira et al. (1995) e Zanin \& Mota (1995) não detectaram influência do nitrogênio sobre a qualidade fisiológica das sementes de trigo e quiabo.

Em cebola, Thomazelli et al. (1992) constataram efeito positivo da adubação com nitrogênio e fósforo sobre o vigor das sementes. Resultados contraditórios foram encontrados em sementes de girassol (Campos \& Sader, 1985), quiabeiro (Zanin \& Mota, 1995), feijão-comum (Paulino et al., 1999) e em feijão-caupi (Oliveira et al., 2000). 


\section{Emergência em campo}

Quanto a emergência em campo, em função de nitrato de cálcio, ocorreu aumento linear da emergência das plantas, à medida em que se aumentou as doses de nitrogênio, sendo a emergência máxima de $70 \%$, obtida na dose de $100 \mathrm{~kg}_{\text {.ha }}{ }^{-1}$ de N. A dose estimada de $56 \mathrm{~kg} \cdot \mathrm{ha}^{-1}$ de nitrogênio aplicado sob forma de sulfato de amônio proporcionou emergência em campo máxima estimada de 73\%. Para a fonte uréia, obtevese valor máximo estimado de 73\% para a emergência em campo na dose de $51 \mathrm{~kg} \cdot \mathrm{ha}^{-1}$ de N (Figura 4). Pantano et al. (1999) detectaram elevado potencial fisiológico em quatro lotes de feijão-comum, em função da aplicação suplementar de nitrogênio. Resultados divergentes foram encontrados por Nakagawa et al. (1994) e Carvalho et al. (1999), nas culturas da aveia-preta e do feijão-comum, respectivamente, onde não se constatou efeito positivo da adubação nitrogenada sobre o vigor das sementes, avaliado pela emergência em campo

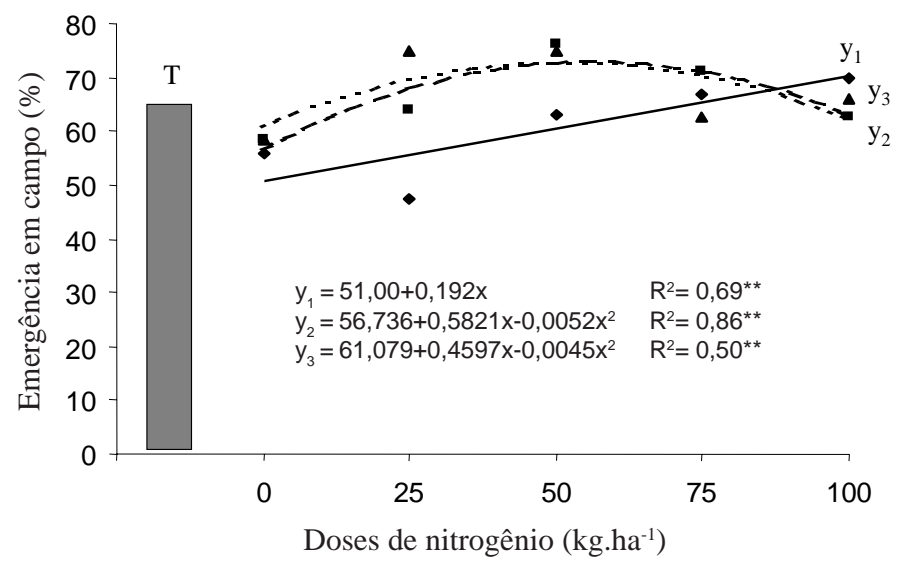

FIG. 4. Emergência em campo de plântulas de feijão-vagem, cv. Macarrão Trepador, em função de doses de nitrogênio, fontes nitrato de cálcio $\left(\mathrm{y}_{1}\right)$, sulfato de amônio $\left(y_{2}\right)$ e uréia $\left(y_{3}\right)$. Areia, 2002.

Os resultados obtidos em função da aplicação das doses de nitrogênio, responsáveis pelos valores máximos, superam a testemunha (67\%) em 2,75; 5,75 e 5,75, respectivamente para nitrato de cálcio, sulfato de amônio e uréia.

\section{CONCLUSÕES}

1. O nitrogênio influenciou positivamente a produção e a qualidade fisiológica de sementes de feijão-vagem.

2. Num programa de produção de sementes de feijão-vagem, a fonte de nitrogênio utilizada deve ser o sulfato de amônio.

\section{REFERÊNCIAS}

ALVES, E.U. Produção e qualidade de sementes de feijão-vagem (Phaseolus vulgaris L.) em função de fontes e doses de matéria orgânica. 1999. 117f. Dissertação (Mestrado) - Centro de Ciências Agrárias, Universidade Federal da Paraíba, Areia.

ALVES, E.U. et al. Produção e qualidade de sementes de feijãovagem em função de fontes e doses de matéria orgânica. Horticultura Brasileira, Brasília, v.18, n.3, p.215-221, 2000.

AMBROSANO, E.J. et al. Efeitos da adubação nitrogenada e com micronutrientes na qualidade de sementes do feijoeiro cv. IAC Carioca. Bragantia, Campinas, v.58, n.2, p.393-399, 1999.

BARBOSA FILHO, M.P.B.; SILVA, O.F. Adubação de cobertura do feijoeiro irrigado com uréia fertilizante em plantio direto: um ótimo negócio. Piracicaba: POTAFOS, 2001. 20p. (POTAFOS Informações Agronômicas, 93).

BEZERRA, A.M.E.; ASSUNÇÃO, M.V. Influência da adubação nitrogenada e espaçamento entre fileiras na produtividade e qualidade das sementes de coentro. Horticultura Brasileira, Brasília, v.13, n.1, p.70,1995.

BRASIL. Ministério da Agricultura e Reforma Agrária. Regras para análise de sementes. Brasília: SNDA/DNDV/CLAV, 1992. 365p.

CAMPOS, M.S.; SADER, R. Efeito da adubação nitrogenada na qualidade da semente de girassol. Revista Brasileira de Sementes, Brasília, v.7, n.3, p.99-106, 1985.

CARNICELLI, J.H. de A. et al. Índices de nitrogênio na planta relacionados com a produção comercial de cenoura. Horticultura Brasileira, Brasília, v 18, p.808-810, 2000. Suplemento.

CARVALHO, M.A.C. de et al. Efeitos de épocas de aplicação e de níveis de $\mathrm{N}$ sobre os teores foliares de $\mathrm{N}$ e de clorofila e suas relações com a produção do feijoeiro. In: REUNIÃO BRASILEIRA DE FERTILIDADE DO SOLO E NUTRIÇÃO DE PLANTAS FERTIBIO, 24., 2000, Santa Maria. Anais... Santa Maria, 2000. p.74.

CARVALHO, M.A.C. et al. Influência de fontes e modos de aplicação de nitrogênio na qualidade fisiológica de sementes de feijão (Phaseolus vulgaris L.) “de inverno”. Informativo ABRATES, Londrina, v.9, n.1/2, p.118, 1999.

CARVALHO, N.M.; NAKAGAWA, J. Sementes: ciência, tecnologia e produção. 4.ed. Jaboticabal: FUNEP, 2000. 588p.

CHIDI, S.N. et al. Resposta do feijoeiro (Phaseolus vulgaris L.) em função da aplicação de doses de nitrogênio em cobertura e em diferentes concentrações de uréia via foliar. I. Características agronômicas. In: REUNIÃO NACIONAL DE FEIJÃO, 6., 1999, Salvador. Resumos expandidos. Santo Antônio de Góias: Embrapa Arroz e Feijão, 1999. p.858-861. (Embrapa Arroz e Feijão. Documentos, 99).

KHOMENMKO, O.M.; LYSYUV, L.A. Effect of mineral fertilizers and irrigations regimes in the growth and development of onion grown for seed. Horticulture Abstract, Ovosh Sadov, v.4, n.3, p.114-119, 1981.

MAGUIRE, J.D. Speed of germination and in selection and evaluation for seedlings emergence and vigor. Crop Science, Madison, v.2, n.2, p.176-177, 1962. 
MENGEL, K.; KIRKBY, E. A. Principles of plant nutrition. 3 ed. Bern: International Potash Institute, 1982. p.295-318.

NAKAGAWA, J. et al. Produção e qualidade de sementes de aveia - preta (Avena strigosa Schreb) em função da adubação nitrogenada. Revista Brasileira de Sementes, Brasília, v.16, n.1, p.95-101, 1994.

OLIVEIRA, A.P. de et al. Produção e qualidade de sementes de feijão-caupi (Vigna unguiculata L. Walp.) cultivado com esterco bovino e adubo mineral. Revista Brasileira de Sementes, Brasília, v.22, n.2, p.102-108, 2000.

OLIVEIRA, A.P. de et al. Produção de feijão-caupi em função de doses de esterco bovino na presença e na ausência de adubo mineral. In: CONGRESSO BRASILERIO DE OLERICULTURA, 39., 1999, Tubarão. Resumos... Tubarão: SOB, 1999.

PANTANO, A.C. et al. Efeitos da aplicação de nitrogênio foliar suplementar em quatro cultivares de feijão (Phaseolus vulgaris L.). II - Qualidade fisiológica de sementes. In: REUNIÃO NACIONAL DE FEIJÃO, 6., 1999, Salvador. Resumos expandidos. Santo Antônio de Góias: Embrapa Arroz e Feijão, 1999. p.553-556. (Embrapa Arroz e Feijão. Documentos, 99).

PAULINO, H.B. et al. Influência do parcelamento de duas fontes nitrogenadas, em cobertura e via fertirrigação, na qualidade fisiológica de sementes de feijão. Informativo ABRATES, Londrina, v.9, n.1/2, p.55, 1999.

POTTKER, D.; ROMAN, E. Efeito de resíduos de culturas e do pousio de inverno sobre a resposta do milho a nitrogênio. Pesquisa Agropecuária Brasileira, Brasília, v.29, n.1 p.763-770, 1994.

PRIMAVESI, A. Manejo ecológico do solo: a agricultura em regiões tropicais. 8.ed. São Paulo: Nobel, 1990. 542p.

SAEG - Sistema para análise estatística, versão 8.0. Viçosa: Fundação Artur Bernardes, 2000.

SILVA, M.A.G. et al. Produção e qualidade de frutos de pimentão cultivado em ambiente protegido em função do nitrogênio e do potássio aplicados em cobertura. Scientia Agrícola, Piracicaba, v.56, n.4, p.1199-1207, 1999.

SORATTO, R.P. et al. Resposta do feijoeiro (Phaseolus vulgaris L.) à aplicação de nitrogênio em cobertura e molibidênio via foliar.
II. Qualidade fisiológica das sementes. In: REUNIÃO NACIONAL DE FEIJÃO, 6., 1999, Salvador. Resumos expandidos. Santo Antônio de Góias: Embrapa Arroz e Feijão, 1999. p.595-598. (Embrapa Arroz e Feijão. Documentos, 99).

TAVARES SOBRINHO, J. Produção e qualidade de feijão-vagem (Phaseolus vulgaris L.) em função de doses e formas de aplicação de nitrogênio. 2001. 100f. Dissertação (Mestrado) - Centro de Ciências Agrárias, Universidade Federal da Paraíba, Areia.

THOMAZELLI, L.F. et al. Efeito do nitrogênio, fósforo e potássio na produção qualidade de sementes de cebola. Revista Brasileira de Sementes, Brasília, v.14, n.2, p.162-165, 1992.

TIMIRIAZEM, K.A. The use of plant analisis of the nutrition system for vegetable plant grow for seed production. Acta Horticulturae, Wageningen, v.29, n.2, p.69-79, 1979.

VALÉRIO, C.R.; ANDRADE, M.J.B.; FURTADO, D.F. Resposta do feijoeiro comum (Phaseolus vulgaris L.) a doses de nitrogênio aplicadas no plantio e em cobertura. REUNIÃO NACIONAL DE FEIJÃO, 6., 1999, Salvador. Resumos expandidos. Santo Antônio de Goiás: Embrapa Arroz e Feijão, 1999. p.866/867. (Embrapa Arroz e Feijão. Documentos, 99).

VELOSO, C.A.C. et al. Resposta de cultivares de pimenta-do-reino aos nutrientes NPK em um latossolo amarelo da amazônia oriental. Scientia Agrícola, Piracicaba, v.57, n.2, p.343-347, 2000.

VIEIRA, R.D.; CARVALHO, N.M. Testes de vigor em sementes. Jaboticabal: FUNEP, 1994, 164p.

VIEIRA, R.D. et al. Efeito de doses e épocas de aplicação de nitrogênio em cobertura na produção e na qualidade fisiológica de sementes de trigo. Científica, São Paulo, v.23, n.2, p.257-264, 1995.

VIGGIANO, J. Produção de sementes de feijão-vagem. In: CASTELLANE, P.D.; NICOLOSI, W.M.; HASEGAWA, M. Produção de sementes de hortaliças. Jaboticabal: Faculdade de Ciências Agrárias e Veterinárias - Fundação de Estudos e Pesquisas em Agronomia, Medicina Veterinária e Zootecnia, 1990. p.127140.

ZANIN, A.C.W.; MOTA, I.F. Efeito de fontes e épocas de aplicação de nitrogênio na produção e qualidade de sementes de quiabeiro. Horticultura Brasileira, Brasília, v.13, n.2, p.167-168, 1995. 